\title{
Multidisciplinary approach to nose vestibule malignancies: setting new standards
}

\author{
Approccio multidisciplinare ai tumori maligni del vestibolo del naso: \\ verso la definizione di nuovi standard
}

\author{
Francesco Bussu'1,4, Luca Tagliaferri², Antonio Piras ${ }^{1}$, Davide Rizzo ${ }^{3}$, Nicola Tsatsaris ${ }^{1}$, Eugenio De Corso ${ }^{4}$, \\ Claudio Parrilla ${ }^{4}$, Gaetano Paludetti ${ }^{4}$ \\ ${ }^{1}$ Otolaryngology Division, Azienda Ospedaliero Universitaria, Sassari, Italy; ${ }^{2}$ Fondazione Policlinico Universitario "A. Gemelli" \\ IRCCS, UOC Radioterapia Oncologica, Dipartimento di Diagnostica per Immagini, Radioterapia Oncologica ed Ematologia, \\ Rome, Italy; ${ }^{3}$ Otolaryngology, Dipartimento delle Scienze Mediche, Chirurgiche e Sperimentali, Università di Sassari, Italy; ${ }^{4}$ UOC \\ di Otorinolaringoiatria, Dipartimento Scienze dell'Invecchiamento, Neurologiche, Ortopediche e della Testa Collo, Fondazione \\ Policlinico Universitario "A. Gemelli” IRCCS, Rome, Italy
}

\section{SUMMARY}

Nose vestibule malignancies, mainly SCCs, are considered rare neoplasms. In the present paper, we review the current state of the art concerning classification and treatment, and describe current evidence supporting a paradigm shift. In the current AJCC classification nose vestibule is considered part of nasal cavity/ethmoid. In daily clinical practice, nose vestibule lesions are often misclassified as skin primaries. This leads to an underestimation of the real incidence and to a mis-management. When nose vestibule primaries are correctly classified as nose primaries, the current AJCC TNM appears inadequate for prognostic stratification and an old staging system described 4 decades ago by Wang has been demonstrated to be more reliable in the literature and is preferred in centers with the largest volume of cases treated. The principles of Wang classification should be applied and nose vestibule acknowledged as a new distinct subsite of nose and paranasal sinuses by the AJCC/ UICC. Surgery, External Beam RadioTherapy (EBRT) and Interventional RadioTherapy (IRT, BrachyTherapy BT) are the current therapeutic options for nose vestibule (NV) SCC. Increasing evidence demonstrates that IRT, with a proper multidisciplinary approach, is at least equivalent to surgery and EBRT for treatment of the primary lesions in terms of oncological outcomes, but markedly superior in terms of cosmetic and functional results, supporting HDR (high dose rate) IRT as the new standard for the treatment of the primary lesion in these malignancies. To optimize the advantages of IRT as primary therapeutic modality we set up a new approach to the implantation phase of IRT exploiting the anatomic planes of esthetic and functional nose surgery and the potential of intensity modulated and image guided brachytherapy to avoid septal and alar perforation (anatomic implantation).

KEY WORDS: nasal vestibule carcinoma, brachytherapy, total rhinectomy, interventional radiotherapy

\section{RIASSUNTO}

I tumori maligni del vestibolo del naso, principalmente SCC, sono considerati neoplasie rare. Nel presente lavoro, rivediamo lo stato attuale dell'arte per quanto riguarda la classificazione e il trattamento, e descriviamo le evidenze attuali a supporto di un cambiamento di paradigma. Nell'attuale classificazione AJCC il vestibolo del naso è considerato parte della cavità nasaleletmoide. Nella pratica clinica quotidiana, le lesioni del vestibolo del naso sono spesso erroneamente classificate come primarie della pelle. Questo porta a una sottovalutazione della reale incidenza e a una cattiva gestione. Quando i tumori primitivi del vestibolo del naso sono correttamente classificati come a origine dal naso/seni paranasali, l'attuale AJCC TNM appare inadeguato per la stratificazione prognostica e un vecchio sistema di stadiazione descritto 4 decenni fa da Wang ha dimostrato di essere più affidabile ed è preferito nei centri con il maggior volume di casi trattati. I principi della classificazione di Wang dovrebbero essere applicati e il vestibolo del naso dovrebbe essere riconosciuto dall'AJCC/UICC come una nuova sottosede distinta di naso e seni paranasali.
Received: October 10, 2020

Accepted: January 15, 2021

Correspondence

Luca Tagliaferri

Fondazione Policlinico Universitario "A. Gemelli" IRCCS

largo F. Vito 1, 00168 Rome, Italy

E-mail: ent.brachytherapy@gmail.com

Funding

None.

Conflict of interest

The Authors declare no conflict of interest.

How to cite this article: Bussu F, Tagliaferri L, Piras A, et al. Multidisciplinary approach to nose vestibule malignancies: setting new standards. Acta Otorhinolaryngol Ital 2021;41(SUPPL.1):S158-S165. https://doi. org/10.14639/0392-100X-suppl.1-41-2021-16

(C) Società Italiana di Otorinolaringoiatria e Chirurgia Cervico-Facciale

\section{(c) (1) $(2)$}

This is an open access article distributed in accordance with the CC-BY-NC-ND (Creative Commons Attribution-NonCommercial-NoDerivatives 4.0 International) license. The article can be used by giving appropriate credit and mentioning the license, but only for non-commercial purposes and only in the original version. For further information: https:// creativecommons.org/licenses/by-nc-nd/4.0/deed.en 
La chirurgia, la radioterapia a fasci esterni (EBRT) e la radioterapia interventistica (IRT, BrachyTherapy BT) sono le attuali opzioni terapeutiche per il carcinoma del vestibolo del naso (NVSCC). Sempre più evidenze dimostrano che la IRT, da effettuarsi in un contesto rigorosamente multidisciplinare, è almeno equivalente alla chirurgia e all'EBRT per il trattamento delle lesioni primarie in termini di esiti oncologici, ma nettamente superiore in termini di risultati estetici e funzionali, supportando l'HDR (high dose rate) IRT come nuovo standard per il trattamento della lesione primaria in questi tumori maligni. Per ottimizzare $i$ vantaggi della IRT come modalità terapeutica primaria abbiamo impostato un nuovo approccio alla fase di impianto della IRT sfruttando i piani anatomici della chirurgia estetica e funzionale del naso e le potenzialità della brachiterapia a intensità modulata e guidata dalle immagini, per evitare la perforazione del setto e dell'ala (impianto anatomico).

PAROLE CHIAVE: carcinoma del vestibolo nasale, brachiterapia, rinectomia totale, radioterapia interventistica

\section{Introduction}

The present work is a critical review of the state of the art concerning nose vestibule squamous cell carcinomas (SCC) with the aim to outline recent evidence supporting a paradigm shift in the domains of classification (1), treatment strategy (2), and therapeutic technique (3, brachytherapy implantation technique).

\section{Nose vestibule malignancy, current classification and misclassification}

The nasal vestibule (NV) is defined as that part of the anterior nasal cavity that is lined by squamous epithelium up to the limen nasi, which is the muco-cutaneous junction ${ }^{1}$. SCC of the nasal vestibule (NV) is a relatively rare condition believed to account for about $1 \%$ of all head and neck malignancies. Primary epithelial malignancies, ad in particular SCCs, of the nasal vestibule, according to the AJCC/ UICC staging system ${ }^{2}$, are classified together and assigned the same topography code (C30.0) than those of the rest of the nasal cavity (nasal cavity proper). A Danish group recently estimated, as a rounded down approximation, an annual incidence of squamous cell of the nasal vestibule of 0.41 per 100.000 inhabitants ${ }^{3}$. Anyway, the absence in the AJCC classification of a specific topography code for nose vestibule malignancies which most often are not discriminated from all the other nasal cavity primaries, as well as the frequent misdiagnosis and misclassification of these lesion as cutaneous neoplasms are likely to produce a relevant underestimation of their incidence. When TNM staging system is concerned, staging criteria for the primary lesion (T) according to AJCC are the same as nasal cavity proper and ethmoid, but anatomical features and peculiar pattern of spread make such criteria clearly inadequate for nose vestibule ${ }^{1-6}$. In fact skin invasion through the nasal valve (mostly deep to alar and superficial to lateral nasal cartilage) is very frequent among SCC of the NV, and makes most of them cT4a for AJCC. On the other hand, paradoxically, bony invasion, which, according to the AJCC, can be present also in cT1 ethmoid/nasal cavity lesions, is typical only of the bulkiest, most difficult to treat and with the worst prognosis, vestibular SCC ${ }^{1,4-6}$. Wang, back in 1976, outlined that "there is no acceptable classification for tumors of the nasal vestibule" and proposed a classification of primary lesions (T), specific for the nose vestibule ${ }^{7}$ (Tab. I). Wang classification has been reported to predict prognosis better than more recent AJCC/UICC T classification and remains the most used for nose vestibule malignancies ${ }^{1,4-6,8,9}$ even if it can result difficult to apply (especially for the distinction between T2 and T3, see Table I).

\section{Rethinking classification and staging of nose vestibule ma- lignancies}

Basing upon the above considerations a shared international standard for classification and staging of nose vestibule malignancies and in particular SCC is needed. We propose 2 modifications of the current TNM.

1. Define the nose vestibule as the portion of the nasal cavity extending from the pyriform aperture to the external skin of the nose, cheek, superior lip, and assign a specific topography code as a site distinct from nasal cavity proper/ethmoid and from maxillary sinus, which are currently the two sites with different $\mathrm{T}$ classification criteria for nose and paranasal sinuses. It will allow to better define the incidence and also to better consider the peculiar aspects of malignancies of the nose vestibule.

2. Set up specific T classification criteria for the newly de-

Table I. Staging of the primary lesions of the nose vestibule according to Wang.

\begin{tabular}{ll}
\hline T1 The lesion is limited to the nasal vestibule, relatively superficial, involving one or more sites within \\
T2 The lesion has extended from the nasal vestibule to its adjacent structures, such as the upper nasal septum, upper lip, philtrum, skin of the nose and/ \\
or nasolabial fold, but not fixed to the underlying bone
\end{tabular}


Table II. A preliminary proposal for redefinition of T classification in nose vestibule malignancies.

\begin{tabular}{|c|c|}
\hline $\mathrm{T} 1$ & The lesion is limited to the nasal vestibule internal surface (skin and or mucosa) \\
\hline T2a & $\begin{array}{l}\text { The lesion invades superficial structures outside the nasal cavity (skin and subcutaneous) and in particular upper lip, philtrum, skin of the nose and/or } \\
\text { nasolabial fold, but does not destroy cartilage, nor invades bony structures, nor structures beyond the plane of the pyriform aperture (septum, lateral } \\
\text { wall, turbinates, etc.) }\end{array}$ \\
\hline T2b & $\begin{array}{l}\text { Disruption of cartilages is evident, without invasion of bony structures, nor of structures beyond the plane of the pyriform aperture (septum, lateral } \\
\text { wall, turbinates, etc.) }\end{array}$ \\
\hline 3 & The lesion extends beyond the pyriform aperture (septum, lateral wall, turbinates, etc.) \\
\hline T4a & The lesion invades bony structures as hard palate, nasal bones, frontal process of the maxilla, ethmoid, and the orbit \\
\hline $\mathrm{rAh}$ & Tumor invades any of the following: orbital apex, dura, brain, anterior and middle cranial fossa, cranial nerves other than (V2), nasopharynx, or clivus \\
\hline
\end{tabular}

fined subsite, starting from the Wang classification, to better define prognosis and guide treatment selection. A hypothetical draft of the new $\mathrm{T}$ classification is reported in table II, considering that, in our experience, cartilage is not usually disrupted in the early phases, but somehow guides tumor spread (posteriorly along the septum, superficially below the alar and above the lateral cartilages to the skin of the dorsum, inferiorly to the superior lip) to different areas of the midface (Fig. 1).

\section{Current treatment options for nose vestibule} SCCs: evidence supporting brachytherapy as the new standard for treatment of the primary lesion

\section{Oncological outcomes}

Surgery, External Beam RadioTherapy (EBRT) and Interventional RadioTherapy (IRT, BrachyTherapy BT) are the current therapeutic options in clinical practice ${ }^{3,9-14}$, as there are not clear evidences of superiority for any modality. Recent papers focusing on the comparison between surgery and IRT ${ }^{4}$ and on IRT alone ${ }^{5,15,16}$ showed that brachytherapy as primary treatment of the $\mathrm{T}$ is not inferior to surgery as

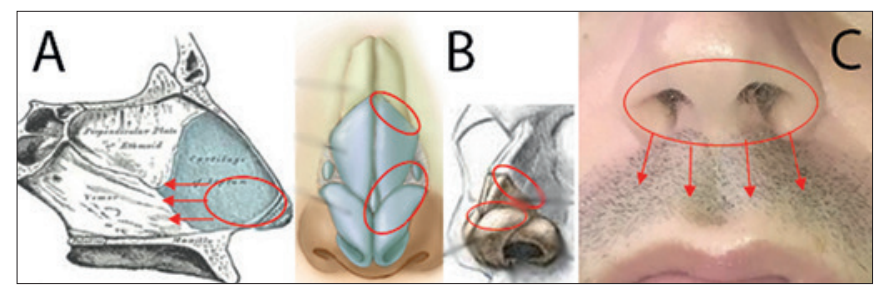

Figure 1. Preferential pattern of local spread of malignancies arising in the nose vestibule. Cartilagineous structures are not usually disrupted in the early phases, as tumor spread rather occurs along them to different areas of the face. Posterior spread along the septum for primaries of the columella and anterior septum is shown in A. Preferential pattern of spread of primaries of the lateral side of the vestibule, between alar and lateral cartilages or (more rare) between lateral cartilage and nasal bones is shown in B. Spread of primaries from columella and inferior side of the vestibule is shown in $\mathbf{C}$. for oncological results (OS over 90\% in cT1 and cT2 according to Wang).

In the absence of oncological evidences supporting one versus another modality, functional issues become fundamental for treatment selection.

\section{Cosmetic outcomes}

Among such functional issues there is for sure the aesthetic appearance, which have obvious social implications and can be deeply impacted by any therapeutic procedure involving the nose and the nose vestibule in particular ${ }^{1,4,6}$. In fact, reconstruction of the nose tip, which shares the cartilaginous framework with the vestibule after ablative surgery, is notoriously extremely difficult for at least 2 reasons:

- it is the most exposed and noticed area of the entire body, where light and human eyes always land. Therefore, minimal imperfections, scars, color mismatches, and deformities exhibit the highest esthetical and social impacts;

- it is practically impossible to faithfully reproduce the complex pattern of relieves and hollows created by the nose cartilage and underlying maxillary and nasal bones using surgical procedures. Free flaps, which have drastically changed head and neck surgical oncology in the last few decades, do not have a resolutive impact here. According to several authors $3,12,18$ bone anchored prostheses remain the best option under an esthetical point of view in case of total rhinectomy defects.

Therefore, anatomical preservation of the osteocartilaginous framework is the most successful option in midface and nose vestibule malignancies from an aesthetic point of view $^{4,12}$. If we consider in addition that nose cartilage itself is generally pretty resistant to radiation, the markedly better cosmetic results reported for high dose rate (HDR) IRT (Fig. 2) when compared to surgery (Fig. 3) ${ }^{4}$ can be easily explained. For the same reasons also EBRT, with similar survival figures than IRT ${ }^{3,13,14}$, is considered a valid alternative option also under an esthetical point of view ${ }^{8,10,12,19,20}$ 
and is probably the most frequently recommended primary treatment in Western countries at present ${ }^{10,19}$.

\section{Functional outcomes}

The nose is primarily part of the respiratory system, being the first section to be passed through by inhaled air. Thus, the nose has evolved multiple physiologic strategies to regulate flow speed, temperature, and humidification (somehow conditioning the inhaled air headed to bronchi and alveoli) of the inspired air, as well as to tightly modulate its ability
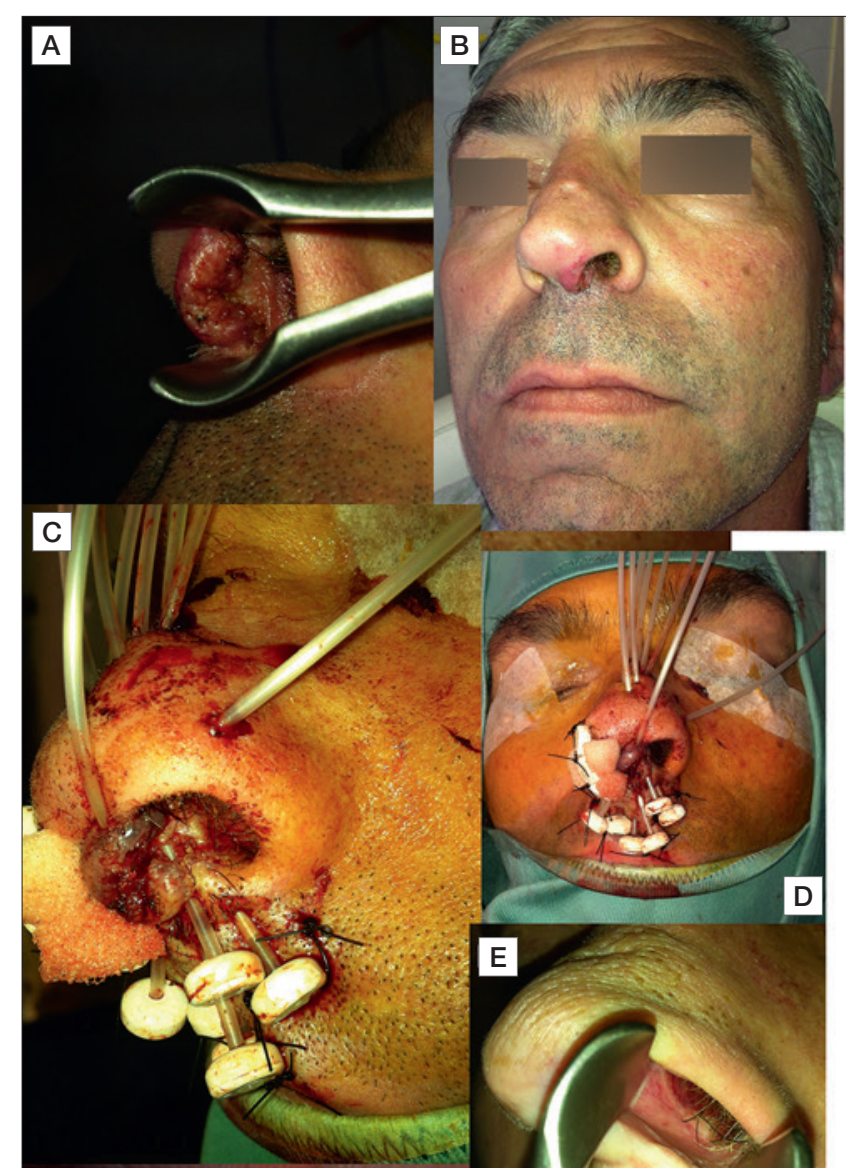

F
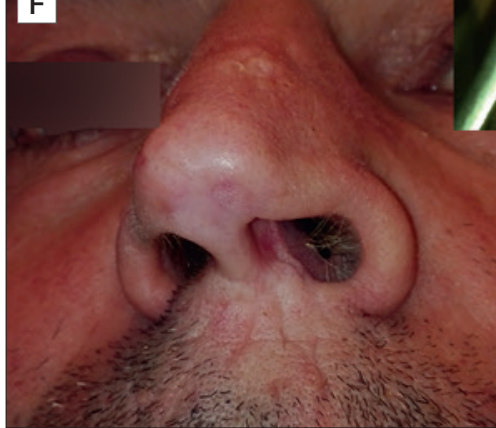
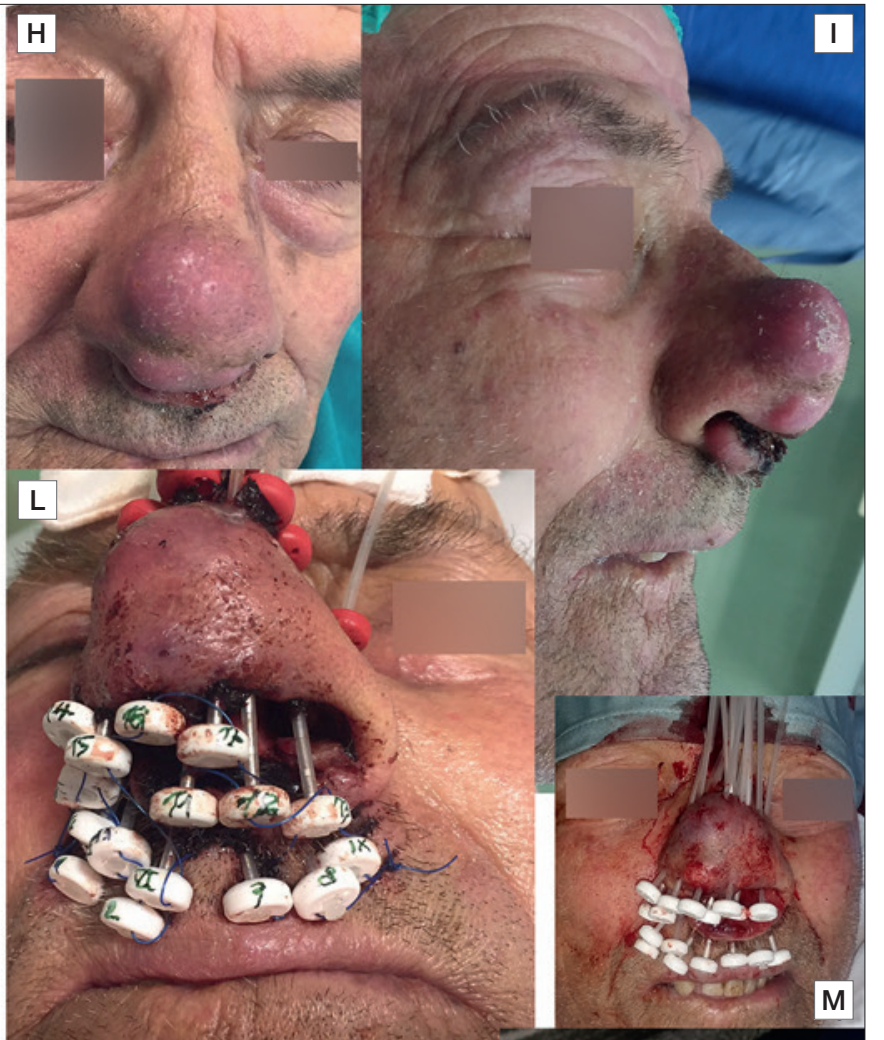

Figure 2. Pretreatment findings $(A, B, H, I)$, catheter positioning $(C, D, L, M)$ and postoperative results $(E, F, G, N, 0)$ in 2 patients treated by primary brachytherapy are shown. Case 1 came to our observation with a primary SCC arising from the columella without a clear cartilagineous involvement (cT1 stage according to Wang). Plastic tubes were placed parallel along the main axis of the nose (C, D) with a complete coverage of the tumor volume. The patient is currently alive with no evidence of disease (60 month follow up) (E). The aesthetic result appears very good (F, G) (pictures have been taken 9 months after treatment). Case 2 displayed a bulky primary SCC (cT2 according to Wang classification, pN1 after concomitant neck dissection), involving all the walls of the nasal vestibule and infiltrating the skin of the nasal dorsum and of the superior lip, and alar and septal cartilages $(\mathbf{H}, \mathbf{I})$. The patient underwent primary brachytherapy and bilateral selective neck dissection. At the time of neck surgery plastic tubes were placed parallel along the main axis of the nose $(\mathbf{L}, \mathbf{M})$ with a complete coverage of the tumor volume). The patient is currently alive with no evidence of disease (30 month follow up). The aesthetic results appear acceptable ( $\mathbf{N}, \mathbf{0})$ (pictures have been taken 7 months after treatment) with no further loss of cartilage deriving from IRT. 

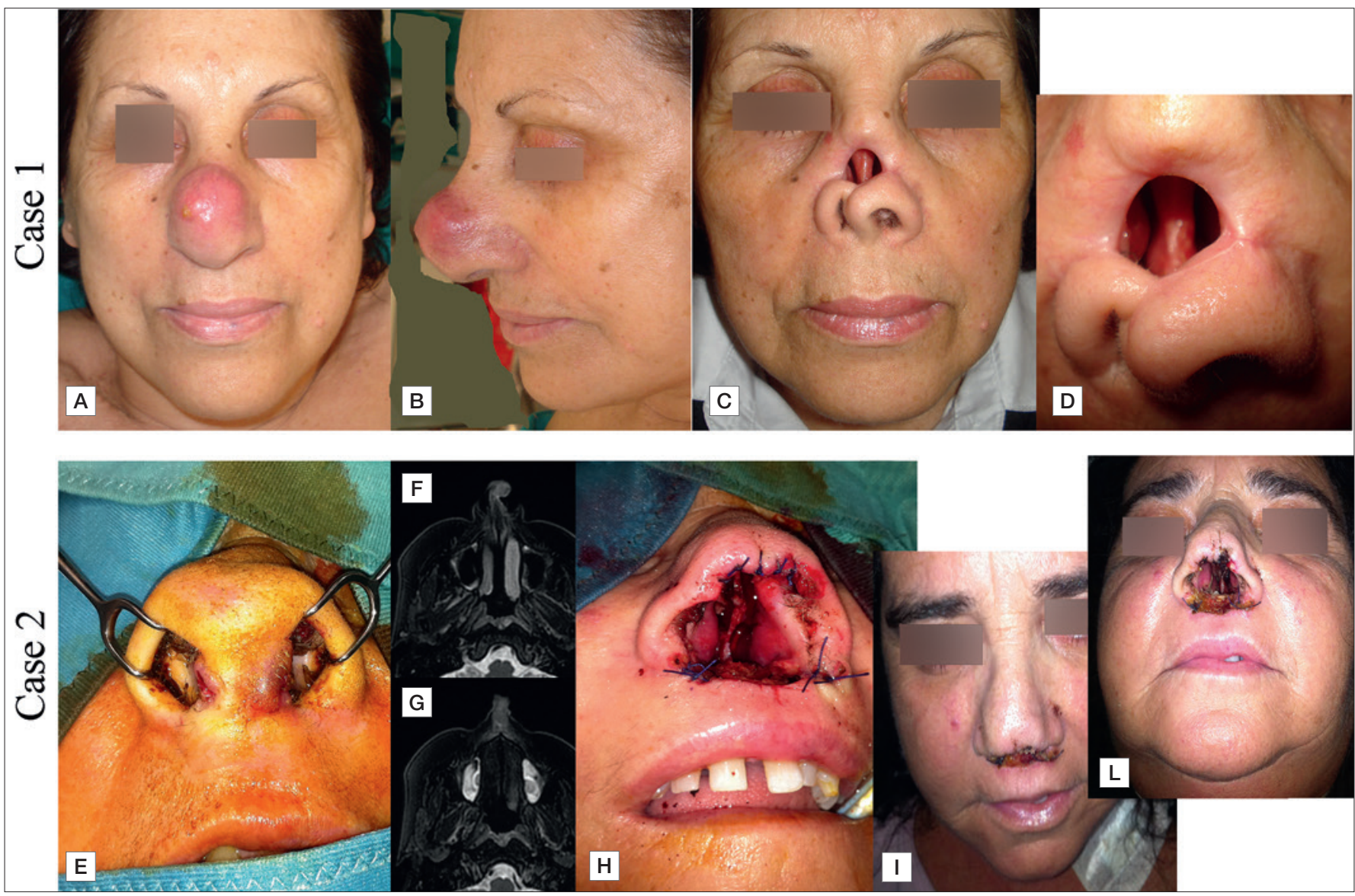

Figure 3. Preoperative findings (A, B, E, F, G) and postoperative results $(\mathbf{C}, \mathbf{D}, \mathbf{H}, \mathbf{I}, \mathbf{L})$ in 2 patients treated by primary surgery are shown. Case 1 came to our observation with a primary SCC arising from the limen nasi and spreading to the tip and the alar skin with cartilagineous involvement (A, B) (T2 stage according to Wang). R0 resection was performed, with the preservation of nostril rims, but the aesthetic result without a prosthesis 12 months after surgery is not satisfactory at all (C, D). Case 2 displayed at physical exam (E) and at MR imaging (F, G) a SCC of the columella spreading towards the superior lip (T2 stage according to Wang). 6 weeks after the $\mathrm{R} 0$ resection, the results of the primary closure are objectively better $(\mathrm{H}, \mathrm{I}, \mathrm{L})$ but still not fully satisfactory for the patient.

to protect and defend itself and the respiratory system as a whole. Among such physiologic strategies, there are the maintenance of adequate intranasal resistances within the physiologic variations due to the nasal cycle ${ }^{21}$, the sneeze reflex ${ }^{22}$, and the complex immunological and mechanical defensive system constituted by nasal mucosa, with all its cellular components (both in the ciliated epithelium and in the stroma) and by the mucous itself. One of the most characteristic and well-known expression of such defensive system is the mucociliary clearance.

Disruption of any of the above-cited physiologic functions can be secondary to gross anatomic variations, as after oncological surgery, or to other pathological processes involving and impairing one or more of the above cited mechanisms, mainly at the level of nose mucosa, as in case of irradiation, which notoriously harbours well known acute and, most of all, late toxicities.

For this reason, knowing that, under a cosmetic point of view, evidence supporting EBRT versus IRT is lacking, we recently compared the 2 irradiation modality as for outcomes on nasal function ${ }^{15}$. The nasal functions are notoriously affected by irradiation ${ }^{23-25}$, and many complaints, as crusting ${ }^{25}$, dry nose ${ }^{26}$, dysosmia ${ }^{24,27}$, dysgeusia ${ }^{24}$, in patients with a previous irradiation of nasal region, are clearly linked to the disruption of physiological mechanisms by mucosal toxicity of radiotherapy ${ }^{26,28,29}$. Most of these previous data have been recently confirmed with specific test after EBRT but not after IRT ${ }^{15}$, with a substantial preservation of nasal function and cytological findings. The rapid dose fall off of the IRT, exploited also in the adjuvant/ perioperative setting ${ }^{30,31}$, with a drastic reduction of the irradiated mucosal surface inside the nasal/paranasal cavities, may be decisive factors. Nevertheless such favourable toxicity profile is well known and exploited also in geriatric population ${ }^{17}$. 
The new standard

Such evidence, together with the confirmation of oncological effectiveness, which remains of course the most relevant argument, supports the establishment of interstitial IRT as the new standard for the treatment of the primary lesion in cT1 and cT2 (according to the Wang staging) NV SCCs. Still, it must not be forgotten that IRT is a multidisciplinary tool at the border between surgery and radiotherapy, and close cooperation between surgeons and radiation oncologists during every phase, from the recommendation of treatment and implantation in the operating theater to the prescription and dose painting at the radiotherapy department, is mandatory to perform high-quality IRT ${ }^{6}$.

\section{Implantation technique for nose vestibule primaries}

The aim of functional and, even more, cosmetic preservation of patients with nose vestibule carcinoma passes as written above through the preservation of the nose tip cartilaginous framework not already eroded by tumour growth. It is well known also from laryngeal oncology ${ }^{32}$ that cartilage itself is particularly resistant to tumour invasion also because it is devoid of blood vessels and fed through the interstitium by direct diffusion from vascularized perichondrium ${ }^{33}$. In fact, as blood vessels are brought in by ossification, probability of invasion drastically increases. Nose cartilages, differently from laryngeal ones, and thyroid cartilage in particular, do not usually get ossified even in the elderly, and in fact, as observed above, direct invasion is very late in nose vestibule SCCs. This fact and the resistance and the low toxicity of radiotherapy on nose cartilages ${ }^{4,15,34-37}$ are clear advantages for the cosmetic results after irradiation of these malignancies.

However, the main reported long-term toxicity of IRT in this area is known to be chondronecrosis and consequent septal and even alar perforations ${ }^{13}$. These sequelae are reportedly more frequent when an interstitial delivery is chosen, than in endocavitary/mold technique ${ }^{13}$, suggesting that chondronecrosis is likely due to the mechanical damage and interruption of the perichondrium which feeds the cartilage by the implants, more than to the dose to cartilage itself. Starting from this assumption, we modified our implantation technique following the principle to avoid as much as possible the piercing of the perichondrium and of the cartilages. To this aim, we leave the implantation phase of nose vestibule SCCs to skilled nose surgeons who brings the plastic tubes along the subperichondral planes, which are the main dissection routes of the functional and aesthetic surgery of the nose (Fig. 4). This implies that the planes of the implant are ideally the subpericondral planes them-

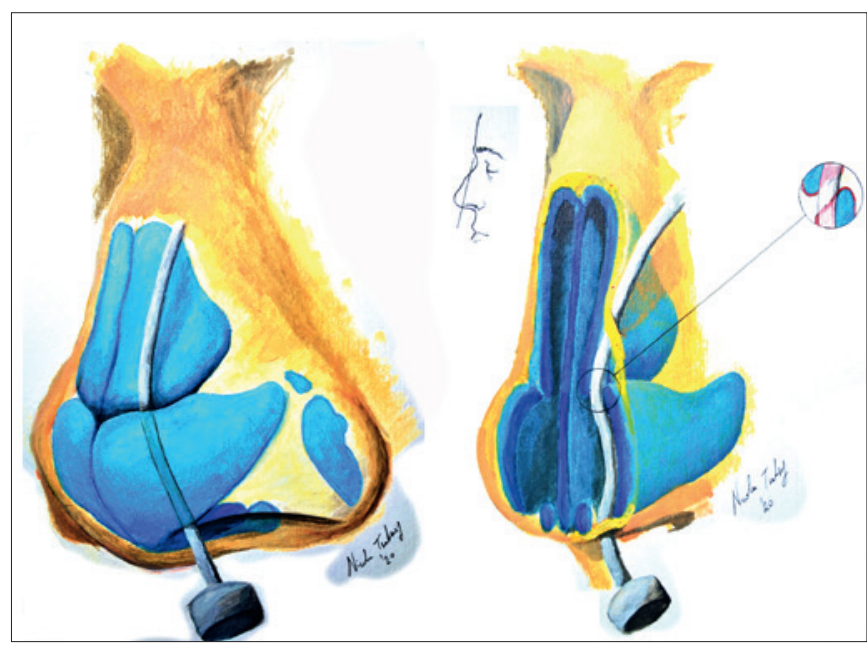

Figure 4. The plastic tubes ideally lie along a subperichondral route, cartilages and perichondrium should not be disrupted and the tubes pass from a submucosal to a subcutaneous plane through the junction between alar and lateral cartilages. Such an implant is particularly fit for a primary lesion invading skin along the same route. More rarely the primary can reach skin through the junction between nasal bone and lateral cartilages, also in this case the implant should follow the same route as malignancy (drawing realised by Nicola Tsatsaris).

selves and that the final geometry of the implant is dictated primarily by the anatomy of the nose tip (and not by the Paris system rules). Such anatomic implantation technique resulted in no septal perforation in our series (39 cases by now) with markedly better functional and cosmetic results than in previous series ${ }^{13}$. The "anatomic" implantation technique may contravene the "classical" Paris system ${ }^{38}$ whose rules and principles remain valid to obtain an optimal dose distribution, especially with LDR linear sources, but the potential of the intensity dose modulation, thanks to the stepping source brachytherapy treatment planning combined with the image guided IRT, can improve dose distribution after "anatomic" implantation in order to obtain optimal local control, which in fact is not inferior to other brachytherapy series $4,6,9,13,15,16$.

\section{Conclusions: towards new standards}

The evidence and the considerations expressed above push for a paradigm shift in different management phases of nose vestibule carcinomas:

- Diagnosis and staging. Nose vestibule should be considered a distinct site of nose and paranasal sinuses, with specific $\mathrm{T}$ staging and criteria borrowed from the most used Wang staging (Tab. I) with some improvements (Tab. II);

- Treatment choice. There are three options available for the treatment of the primary lesion in nose vestibule SC- 
Cs (surgery, EBRT, IRT), without any clear difference in term of oncological outcomes, but IRT (administered with HDR) offers clear advantages in terms of cosmetic and functional results and we consider it the standard for cT1 and cT2 (according to Wang) primary lesion. When there is indication to neck treatment (elective or therapeutic) we recommend concomitant neck dissection, to be performed in the same session as implantation, being IRT a localized treatment, and in case or local/regional recurrence EBRT remains a fully available option;

- IRT technique. The main long term toxicity of IRT on the nose vestibule, which is chondronecrosis deriving from mechanical damage to the perichondrium, can be avoided by an anatomic implantation of the plastic tubes which should lie along the subperichondral planes, exploited for the surgical dissection in the rhinoseptoplasty. Dose distribution can be optimized by intensity modulation and image guidance.

\section{References}

1 Jeannon JP, Riddle PJ, Irish J, et al. Prognostic indicators in carcinoma of the nasal vestibule. Clin Otolaryngol 2007;32:19-23. https:// doi.org/10.1111/j.1365-2273.2007.01353.x

2 Amin MB. AJCC Cáncer Staging Manual Eighth Edition. New York, NY: Springer; 2017.

3 Vital D, Morand G, Huber GF, et al. Outcome in squamous cell carcinoma of the nasal vestibule: a single center experience. Head Neck 2015;37:46-51. https://doi.org/10.1002/hed.23549

4 Bussu F, Tagliaferri L, Mattiucci G, et al. Comparison of interstitial brachytherapy and surgery as primary treatments for nasal vestibule carcinomas. Laryngoscope 2016;126:367-371. https://doi. org/10.1002/lary.25498

5 Tagliaferri L, Fionda B, Bussu F, et al. Interventional radiotherapy (brachytherapy) for squamous cell carcinoma of the nasal vestibule: a multidisciplinary systematic review. Eur J Dermatol 2019;29:417421. https://doiorg/ 10.1684/ejd.2019.3599

6 Bussu F, Tagliaferri L, Mattiucci G, et al. HDR interventional radiotherapy (brachytherapy) in the treatment of primary and recurrent head and neck malignancies. Head Neck 2019;41:1667-1675. https:// doi.org/10.1002/hed.25646

7 Wang CC. Treatment of carcinoma of the nasal vestibule by irradiation. Cancer 1976;38:100-106. https://doi.org/10.1002/10970142(197607)38:1<100::aid-cncr2820380118>3.0.co;2-9

8 Agger A, von Buchwald C, Madsen AR, et al. Squamous cell carcinoma of the nasal vestibule 1993-2002: a nationwide retrospective study from DAHANCA. Head Neck 2009;31:1593-1599. https://doi. org/10.1002/hed.21132

9 Levendag PC, Nijdam WM, van Moolenburgh SE, et al. Interstitial radiation therapy for early-stage nasal vestibule cancer: a continuing quest for optimal tumor control and cosmesis. Int J Radiat Oncol Biol Phys 2006;66:160-169. https://doi.org/10.1016/j.ijrobp.2006.03.041

10 Horsmans JD, Godballe C, Jorgensen KE, et al. Squamous cell carcinoma of the nasal vestibule. Rhinology 1999;37:117-121.

11 Guinot JL, Rembielak A, Perez-Calatayud J, et al. GEC-ESTRO ACROP recommendations in skin brachytherapy. Radiother Oncol 2018;126:377-385. https://doi.org/10.1016/j.radonc.2018.01.013
12 Goepfert H. The vex and fuss about nasal vestibule cancer. Head Neck 1999;21:383-384. https://doi.org/10.1002/ (sici)1097-0347(199908)21:5<383::aid-hed1>3.0.co;2-\#

13 Lipman D, Verhoef LC, Takes RP, et al. Outcome and toxicity profile after brachytherapy for squamous cell carcinoma of the nasal vestibule. Head Neck 2015;37:1297-303. https://doi.org/10.1002/ hed. 23758

14 Koopmann M, Weiss D, Savvas E, et al. Clinicopathological and immunohistochemical characteristics of surgically treated primary carcinoma of the nasal vestibule- an evaluation of 30 cases. Clin Otolaryngol 2015;40:240-247. https://doi.org/10.1111/coa.12359

15 Bussu F, Tagliaferri L, De Corso E, et al. Functional results of exclusive interventional radiotherapy (brachytherapy) in the treatment of nasal vestibule carcinomas. Brachytherapy 2021;20:178-184. https:// doi.org/10.1016/j.brachy.2020.08.008

16 Czerwinski MD, van Leeuwen RGH, Kaanders J, et al. Image guided brachytherapy for cancer of the nasal vestibule: local control and cosmesis. Int J Radiat Oncol Biol Phys 2019;103:913-921. https://doi. org/10.1016/j.ijrobp.2018.11.018

17 Lancellotta V, Kovacs G, Tagliaferri L, et al. The role of personalized interventional radiotherapy (brachytherapy) in the management of older patients with non-melanoma skin cancer. J Geriatr Oncol 2019;10:514-517. https://doi.org/10.1016/j.jgo.2018.09.009

18 Wagenblast J, Baghi M, Helbig M, et al. Craniofacial reconstructions with bone-anchored epithesis in head and neck cancer patients - a valid way back to self-perception and social reintegration. Anticancer Res 2008;28:2349-2352.

19 Mendenhall WM, Stringer SP, Cassisi NJ, et al. Squamous cell carcinoma of the nasal vestibule. Head Neck 1999;21:385-393. https://doi. org/10.1002/(sici)1097-0347(199908)21:5<385::aid-hed2>3.0.co;2-r

20 Langendijk JA, Poorter R, Leemans CR, et al. Radiotherapy of squamous cell carcinoma of the nasal vestibule. Int J Radiat Oncol Biol Phys 2004;59:1319-1325. https://doi.org/10.1016/j.ijrobp.2004.01.007

21 Mirza N, Lanza DC. The nasal airway and obstructed breathing during sleep. Otolaryngol Clin North Am 1999;32:243-262. https://doi. org/10.1016/s0030-6665(05)70128-6

22 Nonaka S, Unno T, Ohta Y, et al. Sneeze-evoking region within the brainstem. Brain Res 1990;511:265-270. https://doi. org/10.1016/0006-8993(90)90171-7

23 K1lıç C, Tunçel Ü, Cömert E, et al. The effect of radiotherapy on mucociliary clearance in patients with laryngeal and nasopharyngeal cancer. Eur Arch Otorhinolaryngol 2015;272:1517-1520. https://doi. org/10.1007/s00405-014-3082-7

24 Alvarez-Camacho M, Gonella S, Campbell S, et al. A systematic review of smell alterations after radiotherapy for head and neck cancer. Cancer Treat Rev 2017;54:110-121. https://doi.org/10.1016/j. ctrv.2017.02.003

25 KamelR,Al-Badawy S, KhairyA, et al. Nasal and paranasal sinus changes after radiotherapy for nasopharyngeal carcinoma. Acta Otolaryngol 2004;124:532-535. https://doi.org/10.1080/00016480410018106

26 Surico G, Muggeo P, Mappa L, et al. Impairment of nasal mucociliary clearance after radiotherapy for childhood head cancer. Head Neck 2001;23:461-466. https://doi.org/10.1002/hed.1060

27 Holscher T, Seibt A, Appold S, et al. Effects of radiotherapy on olfactory function. Radiother Oncol 2005;77:157-163. https://doi. org/10.1016/j.radonc.2005.09.015

28 Stringer SP, Stiles W, Slattery WH $3^{\text {rd }}$, et al. Nasal mucociliary clearance after radiation therapy. Laryngoscope 1995;105:380-382. https:// doi.org/10.1288/00005537-199504000-00008

29 Riva G, Boita M, Ravera M, et al. Nasal cytological changes as late effects of radiotherapy for nasopharyngeal cancer. Am J Rhinol Allergy 2015;29:e41-e45. https://doi.org/10.2500/ajra.2015.29.4156 
30 Tagliaferri L, Bussu F, Rigante M, et al. Endoscopy-guided brachytherapy for sinonasal and nasopharyngeal recurrences. Brachytherapy 2015;14:419-425. https://doi.org/10.1016/j.brachy.2014.11.012

31 Tagliaferri L, Bussu F, Fionda B, et al. Perioperative HDR brachytherapy for reirradiation in head and neck recurrences: single-institution experience and systematic review. Tumori 2017:103;516-524. https:// doi.org/10.5301/tj.5000614

32 Mor N, Blitzer A. Functional anatomy and oncologic barriers of the larynx. Otolaryngol Clin North Am 2015;48:533-545. https://doi. org/10.1016/j.otc.2015.04.002

33 Sandell LJ. Novel functions for type II procollagen. Connect Tissue Res 2014;55:20-25. https://doi.org/10.3109/03008207.2013.867340

34 Caccialanza M, Piccinno R, Percivalle S, et al. Radiotherapy of carcinomas of the skin overlying the cartilage of the nose: our experience in 671 lesions. J Eur Acad Dermatol Venereol 2009;23:1044-1049. https://doi.org/10.1111/j.1468-3083.2009.03247.x
35 Caccialanza M, Piccinno R, Moretti D, et al. Radiotherapy of carcinomas of the skin overlying the cartilage of the nose: results in 405 lesions. Eur J Dermatol 2003;13:462-465.

36 Caccialanza M, Piccinno R, Gaiani F, et al. Relevance of dermatologic radiotherapy in the therapeutic strategy of skin epithelial neoplasms: excellent results in the treatment of lesions localized on eyelids and skin overlying the cartilage of the nose. G Ital Dermatol Venereol 2013;148:83-88

37 Caccialanza M, Bertani E, Piccinno R, et al. Radiotherapy of T4 squamous cell carcinoma of the skin of nasal pyramid. J Eur Acad Dermatol Venereol 2006;20:872-874. https://doi. org/10.1111/j.1468-3083.2006.01549.x

38 Chargari C, Van Limbergen E, Mahantshetty U, et al. Radiobiology of brachytherapy: the historical view based on linear quadratic model and perspectives for optimization. Cancer Radiother 2018;22:312318. https://doi.org/10.1016/j.canrad.2017.11.011 